\title{
Parasites of parasites of bats: Laboulbeniales (Fungi: Ascomycota) on bat flies (Diptera: Nycteribiidae) in central
}

\section{Europe}

Danny Haelewaters ${ }^{1 *}$, Walter P. Pfliegler ${ }^{2}$, Tamara Szentiványi ${ }^{3,4,5}$, Mihály Földvári ${ }^{3}$, Attila D. Sándor ${ }^{6}$, Levente Barti ${ }^{7}$, Jasmin J. Camacho ${ }^{1}$, Gerrit Gort ${ }^{8}$, Péter Estók ${ }^{9}$, Thomas Hiller ${ }^{10}$, Carl W. Dick ${ }^{11}$ and Donald H. Pfister ${ }^{1}$

\begin{abstract}
Background: Bat flies (Streblidae and Nycteribiidae) are among the most specialized families of the order Diptera. Members of these two related families have an obligate ectoparasitic lifestyle on bats, and they are known disease vectors for their hosts. However, bat flies have their own ectoparasites: fungi of the order Laboulbeniales. In Europe, members of the Nycteribiidae are parasitized by four species belonging to the genus Arthrorhynchus. We carried out a systematic survey of the distribution and fungus-bat fly associations of the genus in central Europe (Hungary, Romania).

Results: We encountered the bat fly Nycteribia pedicularia and the fungus Arthrorhynchus eucampsipodae as new country records for Hungary. The following bat-bat fly associations are for the first time reported: Nycteribia kolenatii on Miniopterus schreibersii, Myotis blythii, Myotis capaccinii and Rhinolophus ferrumequinum; Penicillidia conspicua on Myotis daubentonii; and Phthiridium biarticulatum on Myotis capaccinii. Laboulbeniales infections were found on 45 of 1,494 screened bat flies (3.0\%). We report two fungal species: Arthrorhynchus eucampsipodae on Nycteribia schmidlii, and A. nycteribiae on N. schmidlii, Penicillidia conspicua, and P. dufourii. Penicillidia conspicua was infected with Laboulbeniales most frequently $(25 \%, n=152)$, followed by $N$. schmidlii $(3.1 \%, n=159)$ and P. dufourii $(2.0 \%, n=102)$. Laboulbeniales seem to prefer female bat fly hosts to males. We think this might be due to a combination of factors: female bat flies have a longer life span, while during pregnancy female bat flies are significantly larger than males and accumulate an excess of fat reserves. Finally, ribosomal DNA sequences for A. nycteribiae are presented.

Conclusions: We screened ectoparasitic bat flies from Hungary and Romania for the presence of ectoparasitic Laboulbeniales fungi. Arthrorhynchus eucampsipodae and A. nycteribiae were found on three species of bat flies. This study extends geographical and host ranges of both bat flies and Laboulbeniales fungi. The sequence data generated in this work contribute to molecular phylogenetic studies of the order Laboulbeniales. Our survey shows a complex network of bats, bat flies and Laboulbeniales fungi, of which the hyperparasitic fungi are rare and species-poor. Their host insects, on the other hand, are relatively abundant and diverse.
\end{abstract}

Keywords: Arthrorhynchus, Bat flies, Ecological specificity, Ectoparasitic fungi, Host specificity, Hyperparasitism

\footnotetext{
* Correspondence: dhaelewaters@fas.harvard.edu

${ }^{1}$ Department of Organismic and Evolutionary Biology, Harvard University,

Cambridge, Massachusetts, USA

Full list of author information is available at the end of the article
}

(c) The Author(s). 2017 Open Access This article is distributed under the terms of the Creative Commons Attribution 4.0 International License (http://creativecommons.org/licenses/by/4.0/), which permits unrestricted use, distribution, and reproduction in any medium, provided you give appropriate credit to the original author(s) and the source, provide a link to the Creative Commons license, and indicate if changes were made. The Creative Commons Public Domain Dedication waiver (http://creativecommons.org/publicdomain/zero/1.0/) applies to the data made available in this article, unless otherwise stated. 


\section{Background}

\section{Bats and bat flies}

Bats (Mammalia: Chiroptera) contain more than 1,300 described species and are the second-most diverse group of living mammals, after rodents [1]. The lineage has evolved numerous adaptations that uniquely and effectively expand their ecological amplitude. These include flight, echolocation and a generally nocturnal lifestyle [2]. Moreover, bats are capable of utilizing a wide variety of food sources including insects, other vertebrates, blood, fruit and nectar. Bats vary greatly in their sociality ranging from solitary to the largest congregations of mammals numbering tens of millions of individuals. Finally, they vary in the roosts they use during day and night, from large and permanent structures such as caves and mines, to intermediate structures such as buildings and hollow trees, to ephemeral structures such as leaf tents and plant foliage [3]. Owing in part to these unique adaptations, bats are also parasitized by a plethora of arthropod lineages, including mites, ticks, bugs, fleas and flies. Among these parasites, the flies (Diptera: Hippoboscoidea: Streblidae and Nycteribiidae) are among the most conspicuous. Commonly known as "bat flies", these specialized insects are known only from bats where they live in the fur and on the flight membranes and feed on blood [4]. Bat flies currently are divided into two families. The family Streblidae contains about 230 described species, which are cosmopolitan but generally richer in the Western Hemisphere. The family Nycteribiidae contains about 275 species, also occurring worldwide but generally more speciose in the Eastern Hemisphere [5]. Both families are considered tropical or subtropical in distribution, though certain species occur at northern or southern latitudes.

The flies are "semi-permanent" parasites with adaptations that help keep them associated with their bat hosts. Adult females rear three larval stages internally, nourished by milk glands, and adults of both sexes generally do not often leave the host bats. One exception are gravid females, who temporarily leave their host to deposit the terminal third-instar larvae on the roost substrate. Here, the larva soon forms a puparium and at approximately three weeks development the new adult emerges to seek a host bat in order to feed and find mates [4]. However, some studies [6] suggest that the duration of European bat fly pupal development is dependent in part upon the presence of bats in the roost. Thus, although larval stages are telescoped and tied to the host via the female fly, there is necessarily a period of off-host development that presents opportunities for flies to interact with other fly and host species inside the roost, and with the roosting environment itself [7]. Despite opportunity to colonize multiple host species, the emerging consensus is that bat flies are quite specific to individual host species, at least in ecological time. Although some experimental work has evaluated host choice and specificity [8, 9], much of our understanding of host specificity comes from large surveys of bats and parasites. When care is taken in the handling of bats and bat flies in the field, a remarkably high degree of host specificity is noted [10]. In particular, bat social structure, the roost environment, and species fidelity to roosting structures play key roles in parasite dynamics $[11,12]$. Bat species that live in large groups and roost in large and long-lived structures that they return to with high fidelity increases parasitism generally, which in turn should raise transmission frequency and opportunities for selection toward parasitism in organisms associated with bats and with bat parasites.

\section{Laboulbeniales}

Laboulbeniales (Fungi: Ascomycota) are microscopic parasites of myriad arthropod hosts. They grow onto the integument of three subphyla within Arthropoda: Chelicerata (infecting only mites), Myriapoda (millipedes), and Hexapoda (insects) [13]. Unlike other multicellular fungi, Laboulbeniales do not grow mycelia or hyphae. Instead they form a thallus (plural: thalli), which is derived from the enlargement and subsequent divisions of a single twocelled ascospore. A thallus typically consists of three major parts: a multicellular receptacle, which attaches to the host through the (often blackened-melanized) foot or rootshaped haustorium that may penetrate the body of the host; a single or multiple perithecia, the spore-forming structure(s); and appendages bearing antheridia, which produce spermatia.

While about $80 \%$ of the currently described species of Laboulbeniales are found on Coleoptera, only $10 \%$ parasitize Diptera [14]. Laboulbeniales parasitizing flies belong to eight genera: Arthrorhynchus Kolenati, Dimeromyces Thaxt., Gloeandromyces Thaxt., Ilytheomyces Thaxt., Laboulbenia Mont. \& C.P. Robin, Nycteromyces Thaxt., Rhizomyces Thaxt. and Stigmatomyces H. Karst. The genus Laboulbenia is by far the largest genus with close to 600 recognized species with a wide array of hosts, and only 24 of those are known from flies [15]. Stigmatomyces is the second-largest genus in the order, with 144 described species, all of which occur on flies [16]. The genera Arthrorhynchus, Gloeandromyces and Nycteromyces are specific to bat flies, while all other genera have never been recorded from these two host families.

Arthrorhynchus is apparently restricted to Eastern Hemisphere species of the Nycteribiidae, which are also most diverse in the Eastern Hemisphere. Thaxter [17] recognized three species: $A$. cyclopodiae Thaxt., A. eucampsipodae Thaxt. and $A$. nycteribiae (Peyr.) Thaxt. Two additional species, $A$. diesingii and $A$. westrumbii, were described in the 1850s [18], but were soon synonymized with Arthrorhynchus nycteribiae (as Helminthophana) [19]. Merola [20] described a fourth species, A. acrandros. 
This species, however, is very similar to $A$. nycteribidae and likely represents the same species. New collections are needed before making a final decision about synonymy because Merola's original material is likely lost (W. Rossi personal communication). Both species $A$. acrandros (Italy) and A. cyclopodiae (Papua New Guinea) are only known from the type collection.

A comprehensive study was conducted by Blackwell [21] to screen nycteribiid bat flies for presence of Arthrorhynchus spp. She screened 2,517 individuals, of which 56 were infected by A. eucampsipodae or A. nycteribiae, denoting an infection prevalence of $2.2 \%$ [21].

The diversity of the other two bat fly infecting genera is restricted, as is knowledge of their distribution and biology. Two species of Gloeandromyces are known: G. nycteribiidarum (Thaxt.) Thaxt. and G. streblae Thaxt. Both species have been reported only once [22], although several aspects of the biology of their hosts have recently been the focus of different studies. Gloeandromyces nycteribiidarum was described on Megistopoda aranea (Coquillett, 1899) (as Pterellipsis aranea) (Streblidae) from Grenada, G. streblae on Strebla wiedemanni Kolenati, 1856 (as S. vespertilionis) (Streblidae) from Venezuela. Nycteromyces is monotypic. Its single species, $N$. streblidinus Thaxt., was described on Strebla wiedemanni (as S. vespertilionis) from Venezuela [23] and has not been reported since. Interestingly, G. streblae and N. streblidinus were described from the same bat fly specimen ("No. 2073/a," deposited at the Harvard Museum of Comparative Zoology). Both Gloeandromyces and Nycteromyces seem restricted in distribution to the Western Hemisphere, where they are associated with host species of the Western Hemisphere clade of the paraphyletic Streblidae [24]. The currently known distributional records, fungus-bat fly and fungus-bat associations are summarized in Fig. 1 and Additional file 1: Table S1. From the two countries considered in this paper, only Arthrorhynchus nycteribiae (Peyr.) Thaxt. is
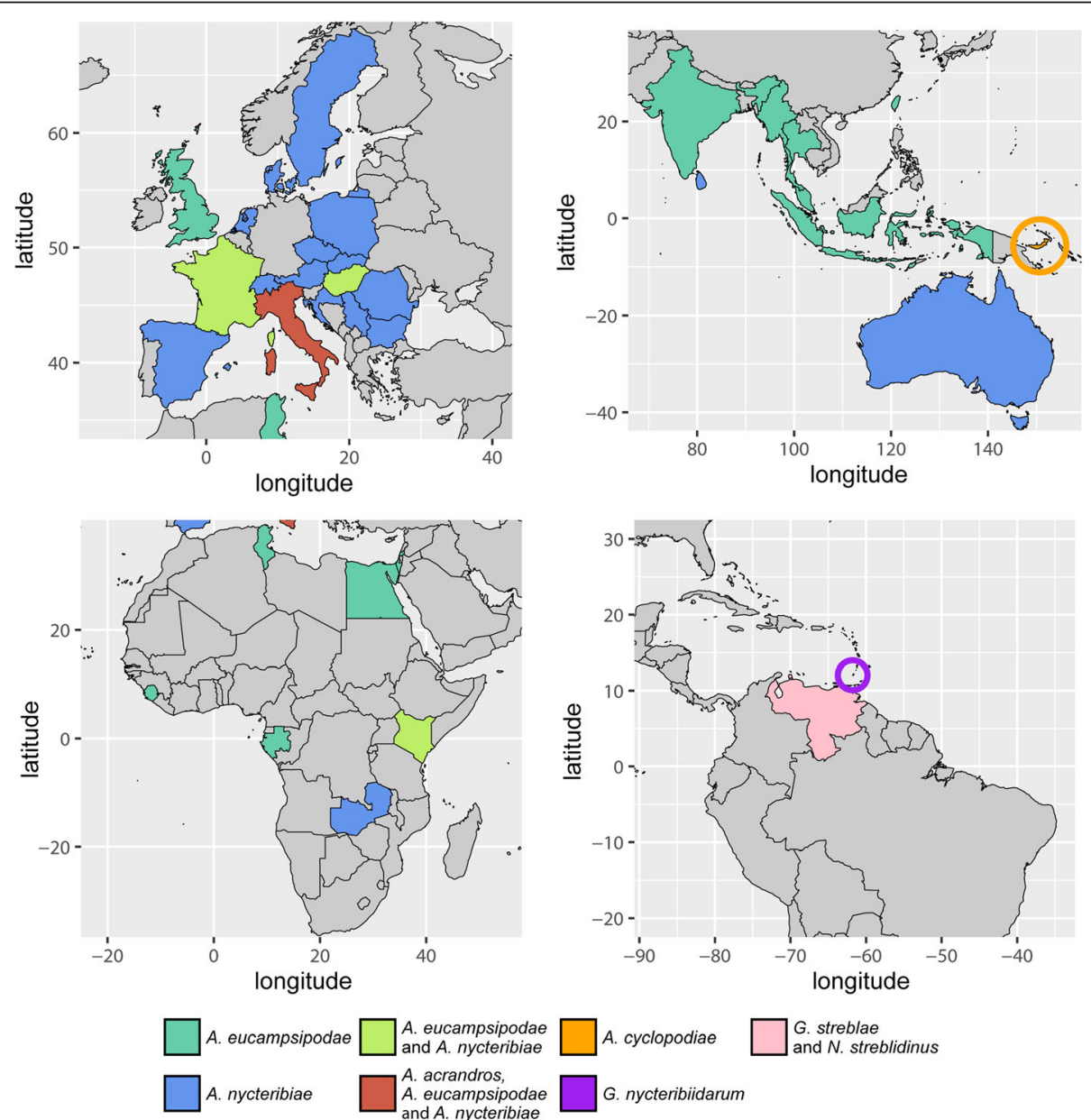

Fig. 1 Review of all bat fly-associated Laboulbeniales. Global distribution of bat fly-Laboulbeniales interactions (up to November 2016). All published records from the literature are incorporated in this figure, as well as the reports from the present paper. For a detailed overview of literature records, see Additional file 1: Table S1 
reported, from the nycteribiid Penicillidia conspicua Speiser, 1901.

Recently, studies on the distribution, population dynamics, host-choice and host-parasite interactions of different Laboulbeniales enabled assessment of the biology of this peculiar fungal group [25-27]. Such studies have successfully focused on locally abundant host insects forming colonies or aggregates (ants and ladybirds). Since bat flies are easily collected during bat surveys and are restricted to microhabitats where they may reach high population densities, they are interesting research targets for similar Laboulbeniales-oriented studies. With this collaborative project we aim to contribute to the research of parasitism of bat flies by Laboulbeniales fungi. The current scantiness of material precludes hypotheses about parasitism, host specificity, etc. As for five species of Laboulbeniales from bat flies only the type collection exists - A. acrandros, A. cyclopodiae, G. nycteribiidarum, G. streblae and N. streblidinus - our first effort has been to collect bat flies and screen these and existing bat fly collections for the presence of Laboulbeniales. Despite having many features that contribute to the difficulties in studying the Laboulbeniales [28], they do remain intact on dead host individuals. This way, historical collections of hosts can be used to record parasite prevalence, host specificity and population dynamics through time [13].

Here we extend geographical and host ranges, and discuss host associations. Our results also illustrate how even decade-old insect collections (with detailed collection data) can be used to uncover new host-parasite networks and the underlying factors.

\section{Methods}

\section{Sampling sites}

Bat flies were collected during bat surveys in the Romanian Carpathians and the Dobrogean Plateau and in various, mainly mountainous parts of Hungary (Transdanubian Mountains, Mecsek Mountains, North Hungarian Mountains) (Fig. 2). Study areas included roosting sites localized in caves and mine galleries. Dates for capturing bats ranged from 1998 to 2015.

\section{Capture of bats and collection of bat flies}

Bats were captured mostly close to roosting sites using mist nets or harp traps located at drinking, foraging and swarming sites. All bats were identified [29] and sex and age was determined for each specimen (whenever possible). Ectoparasitic bat flies were removed using forceps. The only exception to this method is the bat flies from Hungarian bats captured in 1998-1999, which were collected with the help of a Fair Isle Apparatus. The Fair Isle Apparatus method was originally developed for collecting ectoparasites of birds [30]. Bats are placed in a small plastic box but keeping their head outside while ethyl acetate is used as fumigant inside the box. After parasite removal, bats were immediately released at the place of capture.

Preservation and long-term storage of bat flies was in 70 or $87 \%$ ethanol in separate vials (one vial per bat host). A small number of the Romanian flies were collected from corpses of bats found in caves or early emerging ones (Myotis daubentonii, $n=12$, Cheile Turzii, Romania). Identification of bat flies was based on Theodor [31] and Theodor \& Moscona [32]. Voucher specimens are

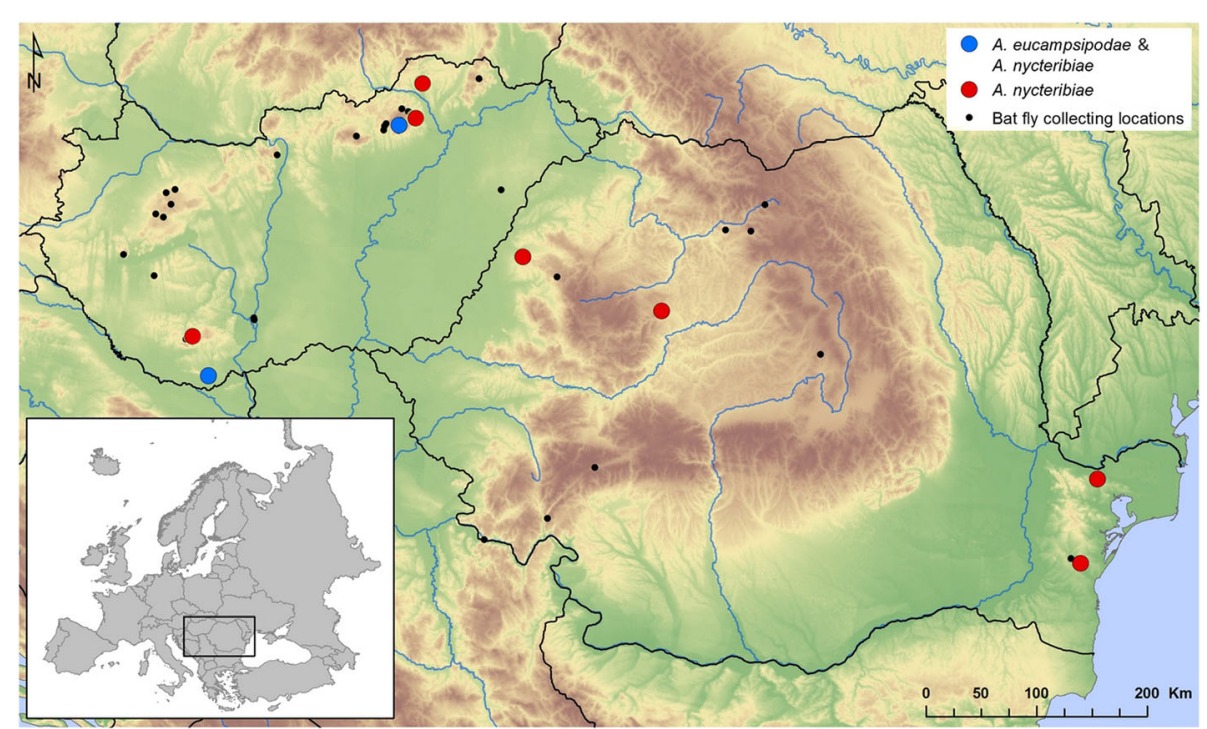

Fig. 2 Geographical map of the studied area. Shown are all sampled locations, with indication of those locations where we found infected bat flies. Arthrorhynchus eucampsipodae is reported only from Hungary, while A. nycteribiae is reported in both Hungary and Romania. Black dots represent locations where no Laboulbeniales fungi were found on the collected bat flies 
deposited at Eszterházy Károly University (Hungary) under accession nos. 12EP01 through 12EP95, 14EP01 through 14EP21, 15EP01 through 15EP07 and P001 through P178. In this study, we collected all ectoparasites from each individual bat to allow prevalence data to be calculated.

\section{Identification of Laboulbeniales}

Bat flies were screened for ectoparasitic fungi using a binocular microscope. Position and density of thalli were detailed and thalli were removed with an entomological pin and slide-mounted for identification [13]. Identification was based on the descriptions and drawings in Thaxter [33]. Voucher slides are deposited at BP (Botanical Department, Hungarian Natural History Museum; nos. 107915 \& 107916) and FH (Farlow Herbarium, Harvard University; no. D. Haelew. 1015c) (details in Additional file 2: Table S2).

DNA extraction from Laboulbeniales, PCR and sequencing Isolation of Laboulbeniales DNA was carried out using the Extract-N-Amp Plant PCR Kit (Sigma-Aldrich, St Louis, MO, USA) and the heat extraction protocol, as outlined in a previous study [28]. PCR amplification of small subunit (SSU) and large subunit (LSU) ribosomal DNA (rDNA) was performed using the following primer combinations: SL122/NSL2 [28, 34] and NS1/NS4 [35] for SSU, LIC24R/LR3 [36, 37] and LR0R/LR5 [37] for LSU. PCR conditions were: denaturation at $94{ }^{\circ} \mathrm{C}$ for $3 \mathrm{~min}$, followed by 35 cycles at $94{ }^{\circ} \mathrm{C}$ for $1 \mathrm{~min}, 50{ }^{\circ} \mathrm{C}$ for $45 \mathrm{~s}$, and $72{ }^{\circ} \mathrm{C}$ for $1: 30 \mathrm{~min}$, and a final extension step of $72{ }^{\circ} \mathrm{C}$ for $10 \mathrm{~min}$. In the case of unsuccessful PCR, a modified touchdown protocol was applied: initial denaturation at $95{ }^{\circ} \mathrm{C}$ for $10 \mathrm{~min}$, followed by 30 cycles at $95{ }^{\circ} \mathrm{C}$ for $1 \mathrm{~min}, 62{ }^{\circ} \mathrm{C}$ for $1 \mathrm{~min}$ (decreasing $1{ }^{\circ} \mathrm{C}$ every 3 cycles), and $72{ }^{\circ} \mathrm{C}$ for $1: 30 \mathrm{~min}$; then 30 cycles with denaturation at $95{ }^{\circ} \mathrm{C}$ for $30 \mathrm{~s}, 55^{\circ} \mathrm{C}$ for $30 \mathrm{~s}$, and $72{ }^{\circ} \mathrm{C}$ for $1 \mathrm{~min}$, and a final extension step of $72{ }^{\circ} \mathrm{C}$ for 7 min. PCR amplification of the internal transcribed spacer (ITS) rDNA was attempted, but without success. PCR products were purified using QIAquick PCR purification kit (Qiagen, Stanford, CA, USA), then sequenced as described in Haelewaters et al. [28]. Generated DNA sequences were assembled and edited in Sequencher 4.10.1 (Gene Codes Corporation, Ann Arbor, MI) and blasted in NCBI GenBank (http://ncbi.nlm.nih.gov/blast/Blast.cgi).

The genus Arthrorhynchus was positioned within the Stigmatomycetinae subtribe (= Stigmatomyceteae [33, 38]) based on the receptacle structure with three superposed cells [21]. This subtribe holds 39 genera [38, 39], among which Corethromyces Thaxt., Hesperomyces Thaxt., Prolixandromyces R.K. Benj., Rhadinomyces Thaxt. and Stigmatomyces H. Karst. Sequences of species in these genera are present in GenBank and thus we blasted our SSU rDNA sequences against the following species:
Corethromyces bicolor (GenBank: AF431762), Corethromyces sp. (AF431761), Hesperomyces coleomegillae (KF266893), Hesperomyces virescens (KU574866), Prolixandromyces triandrus (LT158294), Rhadinomyces pallidus (AF431763), Stigmatomyces borealis (JN835186) and S. limnophorae (AF407576). For the LSU rDNA region, much less Laboulbeniales sequences are available in GenBank. We blasted our LSU rDNA sequences against the following species: Hesperomyces virescens (KU574867) and Prolixandromyces triandrus (LT158295).

\section{Statistical analysis}

Laboulbeniales infection fractions for Penicillidia conspicua, P. dufourii and Nycteribia schmidlii were statistically analyzed using generalized linear mixed models (GLMM), using the R package lme4 [40]. We took the binomial distribution with logit link function for the binary infection score per bat fly (aggregating the binary scores per bat gave no indication of overdispersion). The GLMM contained fixed effects for the three bat fly species, the sex of the bat fly, and their interaction, and random effects for the location and year of data collection. First, the sex effect on infection fraction was studied per bat fly species, and, if allowed, the sex effects were aggregated over the three species.

Hypothesis testing was done using likelihood ratio tests, with $P$-values calculated based on $\chi^{2}$ distributions, declaring an effect significant when $P<0.05$. Outcomes of the test statistics are reported as $X_{d f}^{2}$ with $d f=$ the number of parameters tested simultaneously.

\section{Visualization of the host-parasite-parasite network}

The bat-bat fly-Laboulbeniales associations were visualized with the help of the $\mathrm{R}$ package bipartite [41]. We used weighted data and the function plotweb to build a network showing host-dependencies and prevalence.

\section{Results}

\section{Bats and bat flies}

We sampled 1,594 bats of 28 species. Of these, 997 bats were captured in Hungary (24 species), of which 361 carried bat flies (parasite prevalence of 36\%). In Romania, 597 bats were captured (10 species), of which 186 had bat flies (31\%). Taken together, 547 bats were infected with bat flies, accounting for an overall prevalence of $34 \%$. Details are presented in Table 1 . Infected bats were found with different numbers of bat flies. The highest number of bat flies harvested from a single bat was 21. This was Myotis daubentonii with only Nycteribia kolenatii bat flies from Hungary (sample P161). Overall, M. daubentonii (220 infected bats) carried the highest number of bat flies, with 22 specimens having $\geq 10$ bat flies each. In comparison, also many Miniopterus schreibersii bats 
Table 1 Overview of studied bats. Number of bats of different species surveyed in this study, along with the number of bat fly-infected individuals and number of collection sites where the bat species was recorded

\begin{tabular}{|c|c|c|c|c|c|c|}
\hline \multirow[t]{2}{*}{ Bat species } & \multicolumn{3}{|l|}{ Hungary } & \multicolumn{3}{|l|}{ Romania } \\
\hline & No. of bats & $\begin{array}{l}\text { No. of bats } \\
\text { with bat flies }\end{array}$ & No. of collection sites & No. of bats & $\begin{array}{l}\text { No. of bats } \\
\text { with bat flies }\end{array}$ & No. of collection sites \\
\hline Barbastella barbastellus & 56 & 1 & 20 & & & \\
\hline Eptesicus serotinus & 2 & 0 & 2 & & & \\
\hline Hypsugo savii & 2 & 0 & 2 & & & \\
\hline Miniopterus schreibersii & 89 & 79 & 4 & 242 & 100 & 5 \\
\hline Myotis alcathoe & 31 & 4 & 17 & & & \\
\hline Myotis bechsteinii & 199 & 38 & 23 & & & \\
\hline Myotis blythii & 14 & 7 & 5 & 16 & 9 & 3 \\
\hline Myotis brandtii & 15 & 5 & 7 & & & \\
\hline Myotis capaccinii & & & & 9 & 2 & 1 \\
\hline Myotis dasycneme & 15 & 0 & 9 & & & \\
\hline Myotis daubentonii & 234 & 183 & 28 & 151 & 37 & 4 \\
\hline Myotis emarginatus & 38 & 0 & 10 & & & \\
\hline Myotis myotis & 33 & 20 & 11 & 47 & 19 & 5 \\
\hline Myotis mystacinus & 1 & 0 & 1 & & & \\
\hline Myotis nattereri & 91 & 6 & 15 & 9 & 1 & 1 \\
\hline Nyctalus leisleri & 1 & 0 & 1 & & & \\
\hline Nyctalus noctula & 3 & 0 & 2 & & & \\
\hline Pipistrellus nathusii & 2 & 0 & 2 & & & \\
\hline Pipistrellus pipistrellus & 35 & 0 & 9 & & & \\
\hline Plecotus auritus & 47 & 4 & 15 & & & \\
\hline Plecotus austriacus & 1 & 0 & 1 & & & \\
\hline Plecotus sp. indet. & 1 & 1 & 1 & & & \\
\hline Rhinolophus blasii & & & & 12 & 3 & 1 \\
\hline Rhinolophus euryale & 36 & 1 & 6 & 9 & 3 & 2 \\
\hline Rhinolophus ferrumequinum & 18 & 11 & 6 & 73 & 5 & 3 \\
\hline Rhinolophus hipposideros & 29 & 1 & 10 & & & \\
\hline Rhinolophus mehelyi & & & & 29 & 7 & 2 \\
\hline Vespertilio murinus & 4 & 0 & 3 & & & \\
\hline Total & 997 & 361 & & 597 & 186 & \\
\hline Total both countries & 1,594 & 547 & & & & \\
\hline
\end{tabular}

were infected by bat flies (179), but only one carried $\geq$ 10 bat flies. Altogether 270 different bat specimens had a single bat fly. Numbers of infected bats are given in Table 2, along with minimum and maximum number of bat flies collected per bat. Of the 28 sampled bat species, 13 were not found to host bat flies (46\%). Collection data of all surveyed 1,494 bat fly specimens are listed in Additional file 2: Table S2.

Among the bat fly specimens collected in this study, a new country record for Hungary was found, Nycteribia pedicularia Latreille, 1805, collected from Myotis daubentonii (20 specimens) and Myotis myotis (2 specimens). This fly species was recovered from the sampling localities in Western Hungary (Isztimér, Komló, Mánfa, Olaszfalu, Öcsény and Pogány).

Furthermore, our collections revealed new bat-bat fly associations [42]: Nycteribia kolenatii Theodor \& Moscona, 1954 is reported for the first time parasitizing Miniopterus schreibersii, Myotis blythii, Myotis capaccinii and Rhinolophus ferrumequinum. Similarily, Penicillidia conspicua is reported from Myotis daubentonii and Phthiridium biarticulatum Hermann, 1804 from $M$. capaccinii.

\section{Laboulbeniales on bat flies}

We found infection with Laboulbeniales on 45 of 1,494 bat flies (3\%). All Laboulbeniales belonged in the genus 
Table 2 Overview of bats with bat flies. Number of bats with bat flies per country (Hungary, Romania). Per bat species, the minimum and maximum number of bat flies collected from a single bat as well as the average number of bat flies collected per bat species are given

\begin{tabular}{|c|c|c|c|c|c|}
\hline \multirow[t]{2}{*}{ Bat species } & \multicolumn{2}{|c|}{ No. of bats with bat flies } & \multicolumn{3}{|c|}{ No. of bat flies on bat hosts } \\
\hline & Hungary & Romania & Minimum & Maximum & Average \\
\hline Barbastella barbastellus & 1 & 0 & 1 & 1 & 1.00 \\
\hline Miniopterus schreibersii & 79 & 100 & 1 & 13 & 1.75 \\
\hline Myotis alcathoe & 4 & 0 & 1 & 2 & 1.50 \\
\hline Myotis bechsteinii & 38 & 0 & 1 & 4 & 1.37 \\
\hline Myotis blythii & 7 & 9 & 1 & 4 & 1.81 \\
\hline Myotis brandtii & 5 & 0 & 1 & 1 & 1.00 \\
\hline Myotis capaccinii & 0 & 2 & 2 & 4 & 3.00 \\
\hline Myotis daubentonii & 183 & 37 & 1 & 21 & 4.13 \\
\hline Myotis myotis & 20 & 19 & 1 & 16 & 2.59 \\
\hline Myotis nattereri & 6 & 1 & 1 & 2 & 1.14 \\
\hline Plecotus auritus & 4 & 0 & 1 & 1 & 1.00 \\
\hline Plecotus sp. indet. & 1 & 0 & 2 & 2 & 2.00 \\
\hline Rhinolophus blasii & 0 & 3 & 1 & 2 & 1.67 \\
\hline Rhinolophus euryale & 1 & 3 & 1 & 4 & 2.00 \\
\hline Rhinolophus ferrumequinum & 11 & 5 & 1 & 6 & 2.06 \\
\hline Rhinolophus hipposideros & 1 & 0 & 1 & 1 & 1.00 \\
\hline Rhinolophus mehelyi & 0 & 7 & 1 & 2 & 1.43 \\
\hline Total bats with bat flies & 361 & 186 & & & \\
\hline
\end{tabular}

Arthrorhynchus. In Romania, we recorded A. nycteribiae on Penicillidia conspicua (16 specimens) (Fig. 3) and $P$. dufourii (2 specimens). In Hungary, we found two species of bat fly-associated Laboulbeniales: A. eucampsipodae (Fig. 4a-b, d), a new country record, and $A$. nycteribiae (Fig. 4c, e): Arthrorhynchus eucampsipodae was recorded on Nycteribia schmidlii (4 specimens), while A. nycteribiae was found on P. conspicua (22 specimens) and $N$. schmidlii (1 specimen). Data on the prevalence of Laboulbeniales infection among all bat fly species are presented in Table 3.

Four new sequences determined in this study are deposited in GenBank: Arthrorhynchus nycteribiae from Penicillidia conspicua on Rhinolophus euryale (Hungary, Edelény), 14EP24, SSU KY094496/ LSU KY094497; and A. nycteribiae from P. conspicua on Miniopterus schreibersii (Hungary, Felsőtárkány), 12EP144, isolate D. Haelew. 1015d, SSU KY094498/ LSU KY094499. We blasted our longest SSU (1,075 bp) and LSU rDNA (877 bp) sequences against selected species, listed in Table 4 . The similarity ranged between 87 and 94\% for SSU, and between 85 and 89\% for LSU.

Of the 159 sampled N. schmidlii bat flies, 5 were infected with Laboulbeniales (3.1\%). Four infected flies were females, 1 male. For P. conspicua, 38 of 152 bat flies were infected with Laboulbeniales (25\%). Of these infected flies 31 were female and only 7 were male. For
P. dufourii, 2 of 102 bat flies were infected with Laboulbeniales (2.0\%), both females. (Fig. 5).

Although in all three bat fly species the female infection fractions were higher, in none of them a significant difference between infection fractions of female and male bat flies was found (GLMM: $P$. conspicua: $X_{1}^{2}=3.19$, $P=0.074 ; P$. dufourii: $X_{1}^{2}=2.52, P=0.113 ; N$. schmidlii:

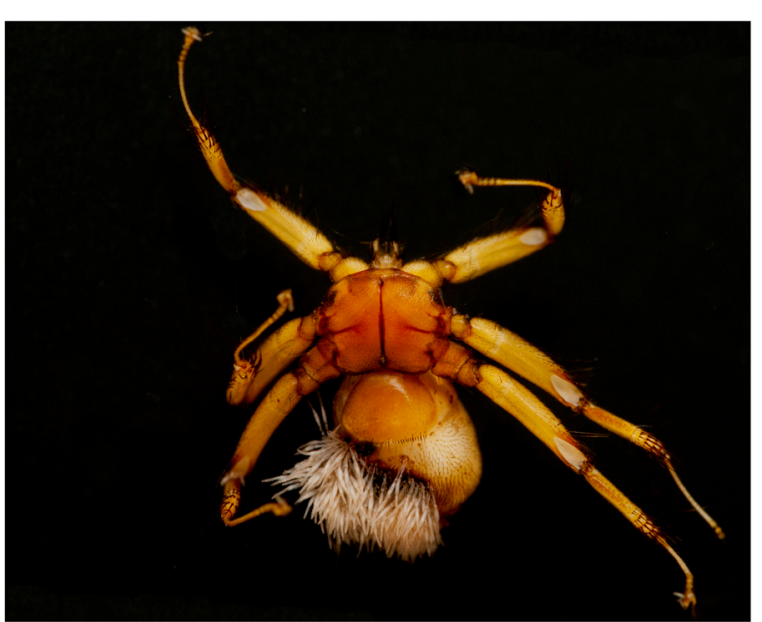

Fig. 3 Heavily infected bat fly Penicillidia conspicua with many thalli of Arthrorhynchus nycteribiae ventrally on its abdomen (sample 101206, Romania) 


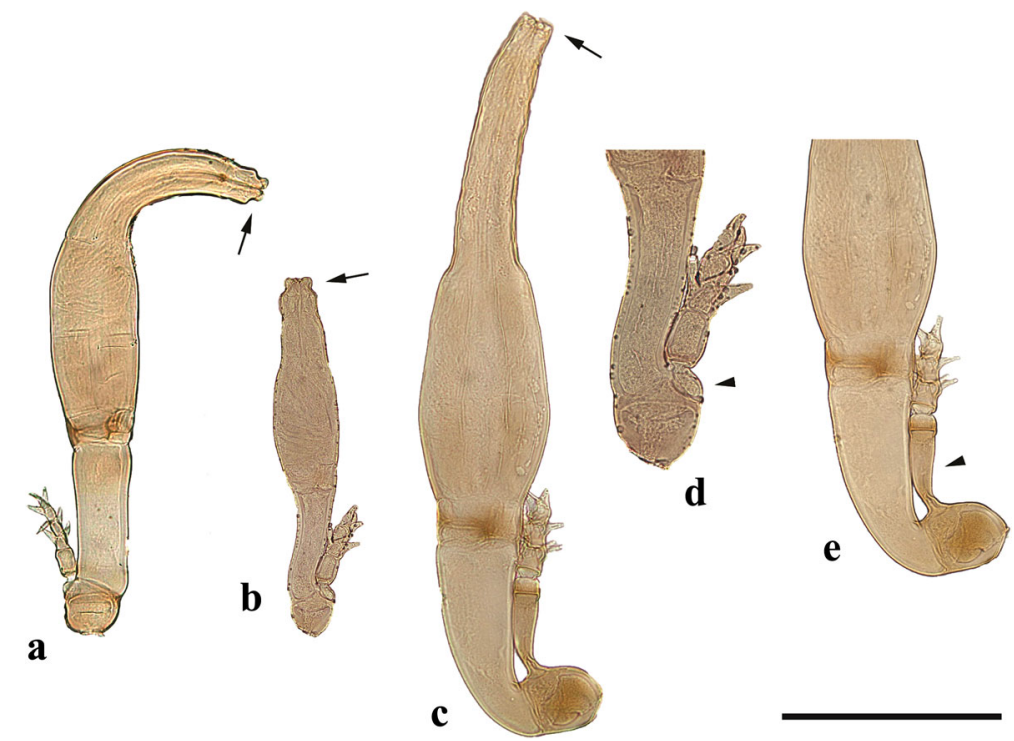

Fig. 4 Arthrorhynchus species encountered during this study. a Single thallus of Arthrorhynchus eucampsipodae with curved perithecium (sample 12EP50). b Single thallus of A. eucampsipodae (sample P052). c Single thallus of Arthrorhynchus nycteribiae (sample 14EP24). d Detail of basal part of A. eucampsipodae (sample P052). e Detail of basal part of A. nycteribiae (sample 14EP24). Both species can be distinguished based on the perithecial tip (arrows in $\mathbf{a}, \mathbf{b}$, and $\mathbf{c}$ ) and cell III of the receptable (arrowheads in $\mathbf{d}$ and $\mathbf{e}$ ). Scale-bar. $\mathbf{a}-\mathbf{c}, \mathbf{e}, 200 \mu \mathrm{m} ; \mathbf{d}, 100 \mu \mathrm{m}$

Table 3 Overview of studied bat flies. Bat fly species sampled from Hungary and Romania during this study, with the prevalence of Laboulbeniales infections and indication of parasite species

\begin{tabular}{|c|c|c|c|c|c|c|c|}
\hline Bat fly species & Bat host & Country & No. sampled & No. infected & $\%$ infected & Country & Laboulbeniales species \\
\hline Basilia italica & All & $\mathrm{H}$ & 13 & 0 & & & \\
\hline Basilia nana & All & $\mathrm{H}$ & 49 & 0 & & & \\
\hline Basilia nattereri & All & $\mathrm{H}$ & 16 & 0 & & & \\
\hline Nycteribia kolenatii & All & $\mathrm{H}, \mathrm{RO}$ & 914 & 0 & & & \\
\hline Nycteribia latreillii & All & $\mathrm{H}$ & 3 & 0 & & & \\
\hline Nycteribia pedicularia & All & $\mathrm{H}$ & 22 & 0 & & & \\
\hline Nycteribia schmidlii & Miniopterus schreibersii & $\mathrm{H}, \mathrm{RO}$ & 147 & 5 & 3.1 & $\mathrm{H}$ & $\begin{array}{l}\text { Arthrorhynchus eucampsipodae (4) } \\
\text { Arthrorhynchus nycteribiae (1) }\end{array}$ \\
\hline Nycteribia schmidlii & Other bat host species & $\mathrm{H}, \mathrm{RO}$ & 12 & 0 & & & \\
\hline Nycteribia vexata & All & $\mathrm{H}, \mathrm{RO}$ & 14 & 0 & & & \\
\hline Penicillidia conspicua & Miniopterus schreibersii & $\mathrm{H}, \mathrm{RO}$ & 142 & 33 & 23.1 & $\mathrm{H}, \mathrm{RO}$ & Arthrorhynchus nycteribiae \\
\hline Penicillidia conspicua & Myotis daubentonii & $\mathrm{RO}$ & 7 & 4 & 57.1 & $\mathrm{RO}$ & Arthrorhynchus nycteribiae \\
\hline Penicillidia conspicua & Myotis blythii & $\mathrm{RO}$ & 2 & 0 & & & \\
\hline Penicillidia conspicua & Rhinolophus euryale & $\mathrm{H}$ & 1 & 1 & 100 & $\mathrm{H}$ & Arthrorhynchus nycteribiae \\
\hline Penicillidia dufourii & Myotis myotis & $\mathrm{H}, \mathrm{RO}$ & 51 & 2 & 3.9 & $\mathrm{RO}$ & Arthrorhynchus nycteribiae \\
\hline Penicillidia dufourii & Other bat host species & $\mathrm{H}, \mathrm{RO}$ & 51 & 0 & & & \\
\hline Phthiridium biarticulatum & All & $\mathrm{H}, \mathrm{RO}$ & 50 & 0 & & & \\
\hline Total & & & 1,494 & 45 & 3.0 & & \\
\hline
\end{tabular}


Table 4 Blast search results for Arthrorhynchus nycteribiae SSU and LSU rDNA sequences (isolate from Edelény). To confirm the accuracy of these newly generated sequences a second isolate was sequenced, from another locality (Felsőtárkány) and another bat host. The first row shows the blast results of the two A. nycteribiae isolates against each other

\begin{tabular}{llllll}
\hline Species & SSU & Isolate & SSU blast (\%) & LSU & Isolate \\
\hline Arthrorhynchus nycteribiae & KY094498 & D. Haelew. 1015d & 99 & KY094499 & D. Haelew. 1015d \\
Corethromyces bicolor & AF431762 & - & $?$ & & \\
Corethromyces sp. AW-2001 & AF431761 & - & 88 & & \\
Hesperomyces coleomegillae & KF266893 & voucher 637 & 94 & & Klast (\%) \\
Hesperomyces virescens & KU574866 & D. Haelew. 655C & 94 & KU574867 & D. Haelew. 655C \\
Prolixandromyces triandrus & LT158294 & Nagyvisnyo1 & 94 & LT158295 & Nagyvisnyo1 \\
Rhadinomyces pallidus & AF431763 & - & 88 & 89 \\
Stigmatomyces borealis & JN835186 & AW-797 & 87 & & \\
Stigmatomyces limnophorae & AF407576 & - & 89 & & \\
\hline
\end{tabular}

$\left.X_{1}^{2}=0.21, P=0.648\right)$. The interaction between bat fly species and sex was not significant (GLMM: $X_{2}^{2}=1.35$, $P=0.510)$. We therefore removed this interaction from the model. In the resulting GLMM we found a significant difference in infection rate between female and male bat flies (averaged over species; $X_{1}^{2}=4.56, P=$ 0.0327 , higher in females), and highly significant differences in infection rates among bat fly species (averaged over sexes; $X_{2}^{2}=52.83, P<0.0001$ ). No extra variation due to year of data collection was found, but variation due to location of data collection was considerable $X_{1}^{2}=$ $12.12(P=0.00025$, obtained by halving the $P$-value from the $\chi_{1}^{2}$ distribution).

Infected $P$. conspicua bat flies were sampled from three different bat hosts: Myotis daubentoni (4 infected

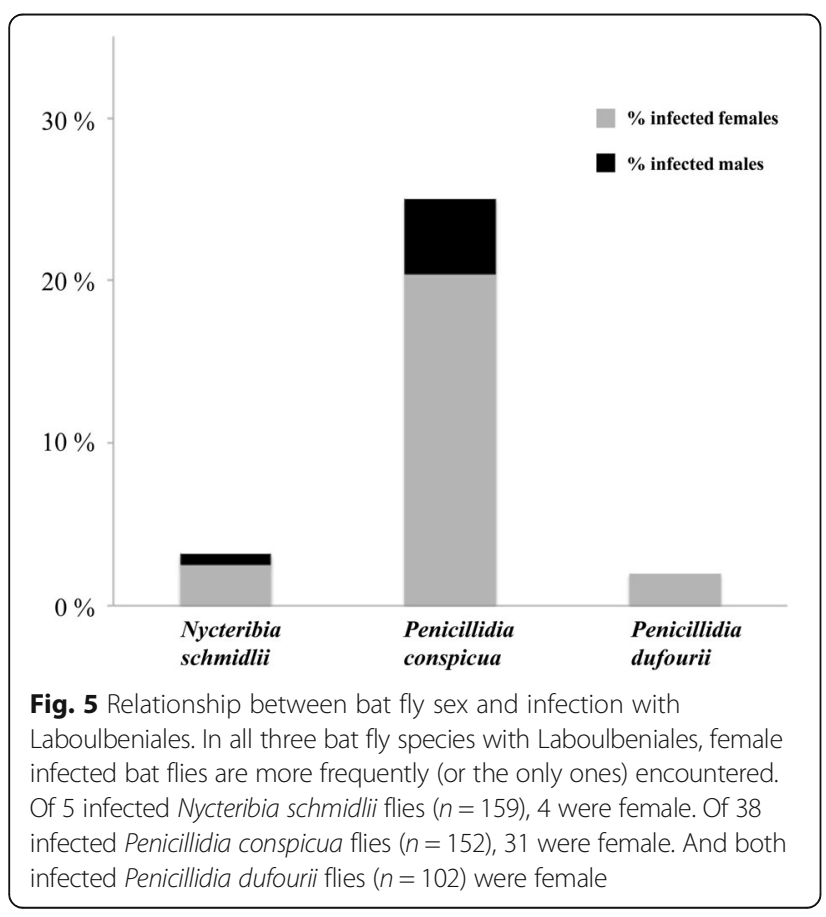

bat flies, $n=7)$; Miniopterus schreibersii (33, $n=142$ ); and Rhinolophus euryale $(1, n=1)$. Infected $P$. dufourii bat flies were found only on the bat Myotis myotis and infected N. schmidlii only on the host Miniopterus schreibersii. A detailed summary, including collecting data, is presented in Additional file 3: Table S3.

\section{Host-parasite-parasite network}

Figure 6 shows the association of bat flies with their bat host as well as the association of Laboulbeniales and their arthropod hosts. The principal bat host for bat flies infected with Laboulbeniales species was $M$. schreibersii for P. conspicua and N. schmidlii. Penicillidia dufourii was found mainly on M. myotis but also occurred commonly on M. blythii and M. schreibersii.

\section{Discussion}

Distribution and associations of bat flies and their bat hosts Bat flies generally have one or two preferred bat hosts upon which they are collected with higher probability compared to other hosts [31, 42]. Our dataset supports these main hosts for the bat flies with a few notable deviations. In the case of Basilia nana we found most flies on Myotis bechsteinii $(n=41)$, one of the two major hosts, and fewer individuals from the other host, $M$. nattereri $(n=4)$. Phthiridium biarticulatum has two major hosts, and we mostly found them on Rhinolophus ferrumequinum $(n=26)$, while the other host species, $R$. hipposideros, is practically missing from our dataset. The new country record for Hungary, Nycteribia pedicularia, has Myotis capaccinii as its main bat host species, but we found it on M. daubentonii $(n=20)$ and M. myotis $(n=2)$.

The new host associations in case of the bat flies $\mathrm{Nyc}$ teribia kolenatii, Penicillidia conspicua and Phthiridium biarticulatum only extend the list of known hosts, since our collecting records support the existing major host species. 


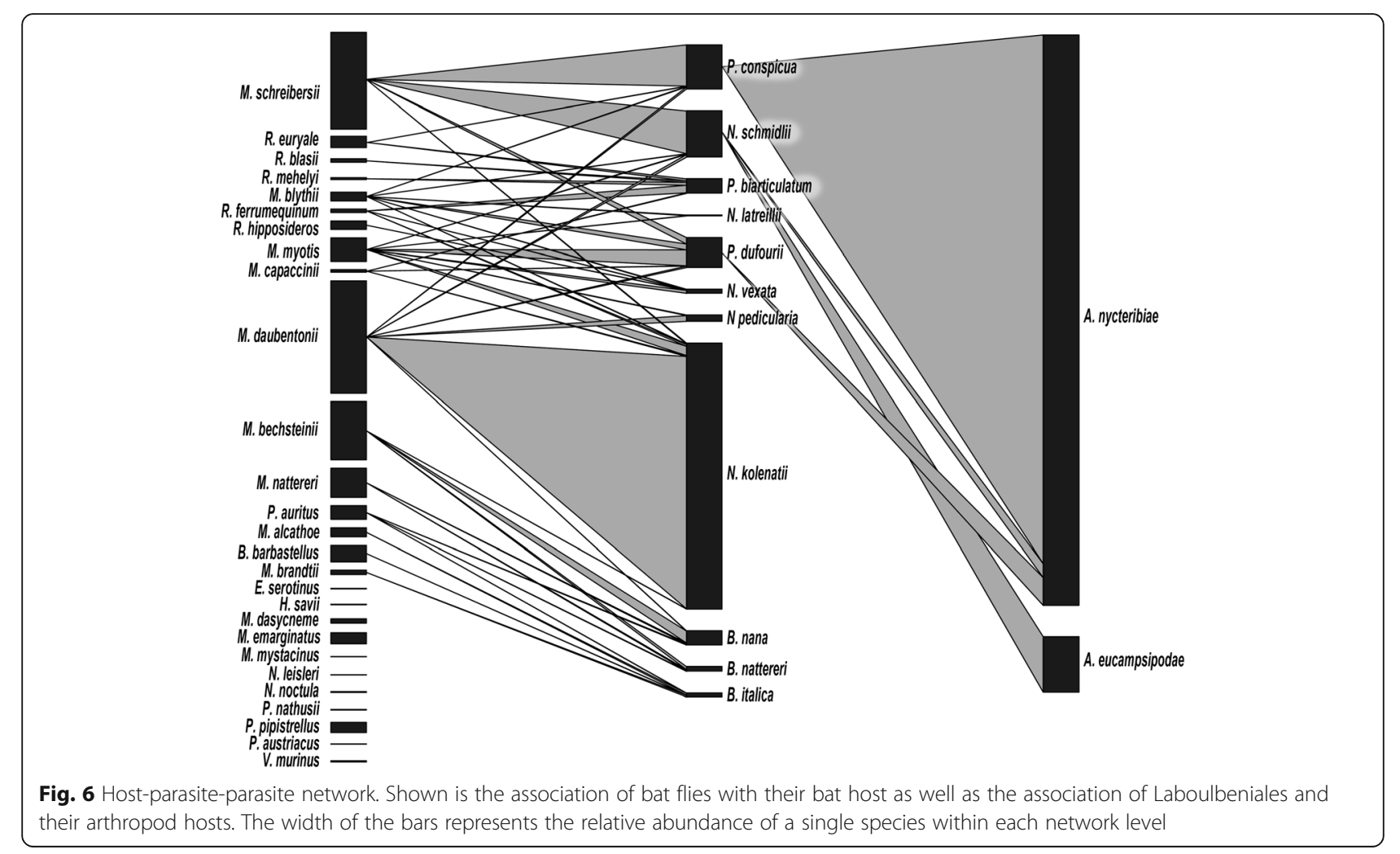

\section{Morphological identification of Arthrorhynchus}

In our circumscription of the genus, three species are accepted: A. cyclopodiae, A. eucampsipodae and A. nycteribiae. The three species can be distinguished based on two morphological characteristics: cell III and the perithecial tip (Fig. 4). Arthrorhynchus nycteribiae is easily separated from the other two species by the elongated cell III, which carries the appendage ([33]: Plate XLVIII, 7-9). In addition, its perithecial tip is four-lobed, with each of the four lobes conspicuously three-lobed ([33]: Plate XLVIII, 10). The perithecial tip of A. eucampsipodae is very similar to that of $A$. nycteribiae but the four lobes are not individually three-lobed. The perithecial tip in $A$. cyclopodiae also ends in four lobes but these are not short and broad as in A. eucampsipodae and $A$. nycteribiae, but erect. Arthrorhynchus cyclopodiae and A. eucampsipodae have similar appendage structures, however there are some differences. In A. eucampsipodae, cell III is constricted in the middle, the upper part of it being conspicuously smaller compared to the lower half; it is also narrower than the basal cell of the appendage ([33]: Plate XLVIII, 14). Cell III of A. cyclopodiae is also constricted in the middle but the upper half is inflated and mostly broader than the base of the basal cell of the appendage ([33]: Plate XLVIII, 3).

Variation in the thallus morphology of A. eucampsipodae was noted by Thaxter [33], who mentioned that its perithecia may be straight or slightly curved distally.
Thalli from the locality Szársomlyó (Fig. 4b) showed straight perithecia, although the other half, those collected in Felsőtárkány (Fig. 4a) showed markedly curved (and somewhat longer) perithecia. Both populations were identical in the cell III and the appendage structure.

\section{DNA sequence data of bat fly-associated Laboulbeniales}

Morphological identification may be insufficient to assess the diversity of Laboulbeniales on (temperate) bat flies. There is the phenomenon of position specificity in Laboulbeniales, in which multiple morphotypes of the same species occupy limited portions of the host's integument [43]. More generally, many fungal species are cryptic, with lineages "hidden" within morphological species complexes. This cryptic diversity is rapidly being uncovered by applying a molecular phylogenetic approach to taxonomic studies [44-46]. In Laboulbeniales, cryptic diversity is a subject of current research, although advances in this field have been hindered by the difficulties in working with and extracting DNA from these fungi [28]. Preservation of material is of utmost importance in successfully extracting DNA from Laboulbeniales: freshly collected host specimens preferably stored in $\geq 95 \%$ ethanol give the best results [28]. To fully understand and discuss the diversity of Laboulbeniales on specific host groups, we need to generate DNA sequences of as many species as we encounter, to be able to add a phylogenetic component to morphological data. 
For this study, we generated the first DNA sequences of $A$. nycteribiae. We generated sequences for two isolates. These isolates were made from bat flies from different bat hosts collected in different locations. Additionally, we applied two distinct DNA isolation methods in two of the collaborating laboratories. The SSU sequences match for 99\% (over $522 \mathrm{bp}$ ) and the LSU sequences are 100\% alike (over $450 \mathrm{bp}$ ). This confirms molecular identity of our isolates. Blasting the SSU rDNA sequence against several species in the Stigmatomycetinae shows that Hesperomyces and Prolixandromyces are more closely related to Arthrorhynchus, compared to Corethromyces, Rhadinomyces and Stigmatomyces. No significant similarity was found with C. bicolor.

Traditionally, the Laboulbeniales (as well as the class Laboulbeniomycetes) are excluded from major phylogenies of the Ascomycota. This is due to a lack of sequence data and the difficulty of working with these fungi . Currently, no broadly inclusive phylogeny of the order is available because of the lack of adequate sampling. However, preliminary data suggest that the Stigmatomycetinae are not a monophyletic group (D. Haelewaters, unpublished data). Generating more DNA sequences and increasing taxon sampling will be important to the resolution of relationships within the Laboulbeniales and to better understand how species have evolved and developed some of their unique traits (such as the formation of a thallus). As to bat fly-associated Laboulbeniales, determining the position of the genera Arthrorhynchus, Gloeandromyces and Nycteromyces within the phylogeny of the order may reveal that they form a single clade or, on the contrary, that multiple colonizations on bat flies from other host groups have happened with subsequent diversification sensu De Kesel \& Haelewaters [47].

The number of thalli of A. eucampsipodae was insufficient for molecular work. We will continue to sample fresh bat flies and screen for Arthrorhynchus spp. from different populations of different host species. We hope this will lead to more sequences. It will be a difficult endeavor to recollect $A$. cyclopodiae, since it is currently only known from the type locality. However, comparing isolates of $A$. nycteribiae taken from different populations of the same host species and from different host species, will give a good estimate of the diversity of Laboulbeniales in this temperate system.

\section{Diversity of bat fly-associated Laboulbeniales in central Europe}

Laboulbeniales exhibit three types of specialization: high specificity to host species (host specificity), growth restricted to certain areas of the host body (position specificity), and speciation resulting from co-habiting hosts (ecological specificity) [43, 47-49].
Arthrorhynchus eucampsipodae is known from species of Basilia, Cyclopodia, Eucampsipoda, Nycteribia and Penicillidia bat flies (Additional file 1: Table S1). Arthrorhynchus nycteribiae has been found on species of Nycteribia, Penicillidia and Phthiridium. In our study, we found only Nycteribia schmidlii, Penicillidia conspicua and P. dufourii infected by Arthrorhynchus eucampsipodae and A. nycteribiae. These three species, together with Phthiridium biarticulatum, are most commonly encountered with Laboulbeniales [21]. Except for being seemingly restricted to Eastern Hemisphere species of Nycteribiidae, there is no strict host specificity, as previously reported [21].

Nycteribia schmidlii was host for both A. eucampsipodae and $A$. nycteribiae in our study. No double infection was found and both fungi were sampled from bat flies from different populations of $M$. schreibersii in Hungary (Additional file 2: Table S2): infection with A. eucampsipodae in Felsőtárkány and Szársomlyó, infection with $A$. nycteribiae in Nagyharsány. Thus far, no double infections have been reported from a single bat fly in the Eastern Hemisphere. This is contrary to the Western Hemisphere, where double infections are observed regularly. Thaxter $[22,50]$ reported a double infection of Gloeandromyces streblae and Nycteromyces streblidinus on Strebla wiedemanni. More recently, we have detected double infections of G. streblae and Gloeandromyces n. spp. on various streblid bat flies from Ecuador, Nicaragua and Panama (D. Haelewaters et al., unpublished data). Physical contact (e.g. mating) between bat flies hosting mature thalli of different Arthrorhynchus species could lead to crossinfection and the presence of double infections on hosts. The main reason for the apparent absence of double infections may simply be the rarity of infected flies, and hence, of contacts between two differently infected flies.

Do bat flies sharing the same bat host carry the same species of Laboulbeniales? If they do share hosts, this would represent an example of ecological specificity. In this situation, the bat skin/fur itself acts as a microhabitat. Also caves, ant nests, and fragmented habitats in salt marshes can be cohabited by multiple, often unrelated hosts $[47,49,51,52]$. In our dataset, we found three bat fly hosts for A. nycteribiae. These are Penicillidia conspicua, P. dufourii and Nycteribia schmidlii. The fungus was present on two specimens of $P$. dufourii and on a single specimen of $N$. schmidlii, while it was associated with 37 specimens of $P$. conspicua. It seems that $P$. dufourii and N. schmidlii are "accidental hosts" and $P$. conspicua the "main host". Penicillidia dufourii uses Myotis myotis and M. blythii but it is also found on Miniopterus schreibersii (20\% in our material). This is probably due to the roost sharing habits of these three bat species; they frequently form mixed colonies in caves 
[53]. Miniopterus schreibersii is the main bat host for $N$. schmidlii and P. conspicua. Furthermore, P. conspicua and $P$. dufourii sometimes choose non-primary hosts if the opportunity arises [54]. Four P. conspicua bat flies and one specimen of $N$. schmidlii from the same Miniopterus schreibersii bat were found infected with A. nycteribiae. Given the record of $A$. nycteribiae on $N$. schmidlii is the only one known in the literature (also not mentioned in [21]), we can safely assume that this infection was the result of an accidental transmission. Indeed, in this occasion the bat host served as the microhabitat allowing transmission of ascospores between hosts. In some cases, shifting between co-occurring hosts can lead to adaptation and eventually to speciation [47]. However, "successful colonization of a new host is probably a rare event" [51] as seems the case with Eastern Hemisphere bat flies.

Our dataset of $\sim 1,500$ bat flies from 15 different bat host species, different habitat types, and geographic locations from Western Hungary to Eastern Romania allows us to speculate on the diversity of Laboulbeniales associated with bat flies in central Europe. We think that the potential for undiscovered species of Laboulbeniales on central European bat flies is very low, and expected only on rarely collected (in this study) bat fly species. Our study revealed no fungi other than A. eucampsipodae and A. nycteribiae after screening 914 Nycteribia kolenatii, 159 N. schmidlii, and 152 P. conspicua specimens. Also Blackwell [21], after screening 2,937 bat fly specimens, did not make any note of undescribed diversity of Arthrorhynchus.

\section{Unbalanced sex ratios of infection}

Generally, female and juvenile bats are more heavily infected by ectoparasites compared to males [3, 55-60]. Furthermore, pregnant individuals are more parasitized by bat flies than non-pregnant females [57]. Dick and Patterson [61] found significantly more male than female bat flies on Venezuelan bats ( $>36,500$ bat flies included in the survey). This phenomenon was potentially explained by selective host grooming, which removes and/or kills the larger females.

In our dataset, we see a clear preference of Laboulbeniales infections on female bat flies. Thus far in Laboulbeniales, sex-related infection patterns are the direct result of mating behavior of the host. For example, in summertime, Hesperomyces virescens Thaxt. occurs mainly at the dorsoposterior of females and the ventroposterior of males [62-64]. Other examples are Cantharomyces denigratus Thaxt./C. italicus Speg. [65], Chitonomyces spp. [43] and Monoicomyces matthiatis T. Majewski [66].

For bat fly-associated Laboulbeniales other factors seem at play. First, female bat flies live longer than males and have an average life span of about 5-6 weeks [67]. Laboratory studies of Basilia hispida Theodor, 1967 bat flies (Nycteribiidae) revealed that males lived for at least 97 days, while females lived for at least 156 days [67]. It could be that the fungal parasites need this time for successful development, maturation, and build-up of inoculum. Second, during pregnancy, female bat flies are significantly larger than males-at extrusion, prepupae may comprise about one third of the body size of the female fly. Moreover, a descriptive modeling study on tsetse flies (Glossinidae: Glossina spp.), which belong to the same superfamily as bat flies (Hippoboscoidea), demonstrated that during each pregnancy females accumulate an excess of fat reserves [68], which are manifested as lobes in the haemolymph for maximal exposure [69, 70]. Such reserves represent higher nutritional resources in female flies for parasites such as Laboulbeniales relative to males. A combination of these factors may lead to a greater infection prevalence on female bat flies, as we have observed.

\section{Conclusions}

Our knowledge about Laboulbeniales fungal ectoparasites of bat flies is poor. Seven species in three genera are recognized based on morphological descriptions, although one species is doubtful. Of those seven, four species are only known from the type collections, which are between 65 and 116 years old. For this paper, we collected bat flies from captured bats in central Europe (Hungary, Romania) and screened them for presence of Laboulbeniales. Our survey shows a complex network of bats, bat flies and Laboulbeniales. New bat-bat fly associations are reported: Nycteribia kolenatii on Miniopterus schreibersii, Myotis blythii, Myotis capaccinii and Rhinolophus ferrumequinum; Penicillidia conspicua on Myotis daubentonii; and Phthiridium biarticulatum on Myotis capaccinii. While the bat flies were relatively abundant and diverse (studied material), the Laboulbeniales associated with them were rare and species-poor. Laboulbeniales were found on 45 of 1,494 screened bat flies: Arthrorhynchus eucampsipodae was reported on Nycteribia schmidlii, and A. nycteribiae on N. schmidlii, Penicillidia conspicua and P. dufourii. Penicillidia conspicua was infected most often, followed by N. schmidlii and P. dufourii. The bat fly Nycteribia pedicularia and the fungus Arthrorhynchus eucampsipodae represent new country records for Hungary. We generated SSU and LSU ribosomal DNA sequences for A. nycteribiae. These are the first sequences for any species of bat fly-associated Laboulbeniales.

\section{Additional files}

Additional file 1: Table S1. Summary of all records of Laboulbeniales associated with bat flies thus far. (XLS $53 \mathrm{~kb}$ )

Additional file 2: Table S2. Collection data of all 1,494 bat fly specimens sampled in this study and screened for presence of Laboulbeniales. Infected bat flies are highlighted and documentation is provided about the 
identification of the fungus and the position(s) on which thalli were found. (XLS $395 \mathrm{~kb}$ )

Additional file 3: Table S3. Data for the 45 bat flies infected with Laboulbeniales fungi encountered during this study. Given are bat and bat fly species, sex of bat and bat fly $(F=$ female, $M=$ male), country $(\mathrm{H}=$ Hungary, $\mathrm{RO}=$ Romania) and locality, year of collection, and position of infection on the bat fly host. (DOC $86 \mathrm{~kb}$ )

\section{Abbreviations}

BP: Unique identifier for the herbarium at the Botanical Department, Hungarian Natural History Museum (consistent with Index Herbariorum); FH: Unique identifier for the Farlow Herbarium at Harvard University (consistent with Index Herbariorum); GLMM: Generalized linear mixed models; ITS: The internal transcribed spacer region of ribosomal DNA; LSU: The large subunit of ribosomal DNA; PCR: Polymerase chain reaction; rDNA: Ribosomal DNA; SSU: The small subunit of ribosomal DNA

\section{Acknowledgements}

The authors thank Sándor Boldogh (Aggtelek National Park Directorate, Jósvafö, Hungary), Tamás Görföl (Hungarian Natural History Museum, Budapest), and Péter Paulovics (Szeged, Hungary) for bat fly samples from Hungary. The survey was organized in the framework of the EurNegVec COST Action TD1303.

\section{Funding}

DH acknowledges funding from the Smithsonian Tropical Research Institute Short-Term Research Fellowship. WPP was supported through the ÚNKP164IV New National Excellence Program of the Hungarian Ministry of Human Capacities. The framework of Domus Hungarica, Hungarian Academy of Science provided financial help to ADS. PE was supported by the European Union and the State of Hungary, co-financed by the European Social Fund in the framework of TÁMOP-4.2.4.A/2-11/1-2012-0001 "National Excellence Program". The funders had no role in the design of the study and in the collection, analysis, and interpretation of data and in writing the manuscript.

\section{Availability of data and materials}

Datasets supporting the conclusions of this article are included within the article and its additional files. Voucher specimens of bat flies (in ethanol) are deposited at Eszterházy Károly University (Hungary) under accession nos. 12EP01 through 12EP95, 14EP01 through 14EP21, 15EP01 through 15EP07, and P001 through P178. Voucher slides of Laboulbeniales are deposited at BP (Botanical Department, Hungarian Natural History Museum; no. 107915, A. eucampsipodae; no. 107916, A. nycteribidae) and FH (Farlow Herbarium, Harvard University; no. D. Haelew. 1015c, A. nycteribiae). Four sequences have been deposited to NCBI GenBank: Arthrorhynchus nycteribiae from Penicillidia conspicua on Rhinolophus euryale (Hungary, Edelény), no. 14EP24, accession nos. KY094496 (SSU) \& KY094497 (LSU); and A. nycteribiae from P. conspicua on Miniopterus schreibersii (Hungary, Felsőtárkány), no. 12EP144, isolate D. Haelew. 1015d, accession nos. KY094498 (SSU) \& KY094499 (LSU).

\section{Authors' contributions}

DH initiated and oversaw the study and wrote the first draft of the manuscript. ADS, LB and PE captured and identified bats. TS, ADS, LB and PE sampled bat flies. TS, MF and PE identified bat flies. TS and MF screened bat flies for Laboulbeniales. DH and WPP identified Laboulbeniales and extracted fungal DNA. TH made Fig. 1 and constructed the host-parasite-parasite association network. CWD participated in writing the first draft of the manuscript. All authors read and approved the final manuscript.

\section{Competing interests}

The authors declare that they have no competing interests.

\section{Consent for publication}

Not applicable.

\section{Ethics approval}

Authorization for bat capture in Romania was provided by the Comisia Patrimoniului Speologic (Speleological Heritage Committee, Ministry of Environment, Waters and Forests, Bucharest, Romania) (No. 305/22.09.2015). In Hungary, authorization was provided by the Országos Környezetvédelmi és Természetvédelmi Főfelügyelőség (National Inspectorate for Environment and Nature Conservation) (No. 14/2138-7/2011).

\section{Author details}

'Department of Organismic and Evolutionary Biology, Harvard University, Cambridge, Massachusetts, USA. ${ }^{2}$ Department of Biotechnology and Microbiology, University of Debrecen, Debrecen, Hungary. ${ }^{3}$ Department of Evolutionary Zoology and Human Biology, University of Debrecen, Debrecen, Hungary. ${ }^{4}$ Department of Ecology and Evolution, University of Lausanne, Lausanne, Switzerland. ${ }^{5}$ Museum of Zoology, Lausanne, Switzerland. ${ }^{6}$ Department of Parasitology and Parasitic Diseases, University of Agricultural Sciences and Veterinary Medicine, Cluj-Napoca, Romania. ${ }^{7}$ Romanian Bat Protection Association, Satu Mare, Romania. ${ }^{8}$ Biometris, Wageningen University, Wageningen, The Netherlands. ${ }^{9}$ Department of Zoology, Eszterházy Károly University, Eger, Hungary. ${ }^{10}$ Institute of Evolutionary Ecology and Conservation Genomics, University of Ulm, Ulm, Germany. ${ }^{11}$ Department of Biology, Western Kentucky University, Bowling Green, Kentucky, USA.

Received: 17 November 2016 Accepted: 8 February 2017

Published online: 21 February 2017

\section{References}

1. Teeling E, Springer M, Madsen O. A molecular phylogeny for bats illuminates biogeography and the fossil record. Science. 2005;307:580-3.

2. Simmons NB, Conway TM. Evolution of ecological diversity in bats. In: Kunz T, Fenton MB, editors. Bat ecology. Chicago: University of Chicago Press; 2003. p. 493-535.

3. Patterson BD, Dick CW, Dittmar K. Sex biases in parasitism of Neotropical bats by bat flies (Diptera: Streblidae). J Trop Ecol. 2008;24:387-96.

4. Dick CW, Patterson BD. Bat flies: Obligate ectoparasites of bats. In: Morand S, Krasnov B, Poulin R, editors. Micromammals and macroparasites: from evolutionary ecology to management. Tokyo: Springer; 2006. p. 179-94.

5. Dick CW, Dittmar K. Parasitic bat flies (Diptera: Streblidae and Nycteribiidae): host specificity and potential as vectors. In: Klimpel S, Melhorn $\mathrm{H}$, editors. Parasitology Research Monographs (Vol. 5): Bats (Chiroptera) as vectors of diseases and parasites. Berlin Heidelberg: Springer; 2014. p. 131-55.

6. Reckardt K, Kerth G. The reproductive success of the parasitic bat fly Basilia nana (Diptera: Nycteribiidae) is affected by the low roost fidelity of its host, the Bechstein's bat (Myotis bechsteinii). Parasitol Res. 2006;98:237-43.

7. Dittmar K, Morse S, Gruwell M, Mayberry J, DiBlasi E. Spatial and temporal complexities of reproductive behavior and sex ratios: a case from parasitic insects. PLoS One. 2011;6:e19438.

8. ter Hofstede HM, Fenton MB. Relationships between roost preferences, ectoparasite density, and grooming behaviour of neotropical bats. J Zool. 2005;266:333-40.

9. Dick CW, Dick SC. Effects of prior infestation on host choice of bat flies (Diptera: Streblidae). J Med Entomol. 2006:43:433-6.

10. Dick CW. High host specificity of obligate ectoparasites. Ecol Entomol. 2007:32:446-50.

11. Lewis SE. Roost fidelity of bats: A review. J Mammal. 1995;76:481-96.

12. Patterson BD, Dick CW, Dittmar K. Roosting habits of bats affect their parasitism by bat flies (Diptera: Streblidae). J Trop Ecol. 2007;23:177-89.

13. Haelewaters D, Zhao SY, De Kesel A, Handlin RE, Royer IR, Farrell BD, Pfister DH. Laboulbeniales (Ascomycota) of the Boston Harbor Islands I: species parasitizing Coccinellidae and Staphylinidae, with comments on typification. Northeast Nat. 2015;22:459-77.

14. Weir A, Hammond PM. Laboulbeniales on beetles: host utilization patterns and species richness of the parasites. Biodivers Conserv. 1997:6:701-19.

15. Rossi W, Kirk-Spriggs AH. A new species of Laboulbenia (Ascomycota) parasitic on an African fly (Diptera: Curtonotidae), with a brief review of Diptera-associated species of the genus. African Invert. 2011;52:211-6.

16. Rossi W, Leonardi M. New species of Stigmatomyces (Laboulbeniomycetes) from Sierra Leone. Plant Biosyst. 2013;147:79-83.

17. Thaxter R. Preliminary diagnosis of new species of Laboulbeniaceae. III. Proc Am Acad Arts Sci. 1901;36:397-414

18. Kolenati FA. Epizoa der Nycteribien. Wien Entomol Monatsschr. 1857;1:66-9.

19. Peyritsch J. Beiträge zur Kenntniss der Laboulbenien. Sitzungsber Kaiserl Akad Wiss Wien, Math-Naturwiss Cl. 1873;68:227-54 
20. Merola A. Interessante ritrovamento di labulbeniologia cavernicola: Arthrorhynchus acrandros n. sp. (con considerazioni sul gen. Arthrorhynchus). Bol Soc Nat Napoli. 1952;60:1-30.

21. Blackwell M. Incidence, host specificity, distribution, and morphological variation in Arthrorhynchus nycteribiae and A. eucampsipodae (Laboulbeniomycetes). Mycologia. 1980;72:143-58.

22. Thaxter R. Contribution towards a monograph of the Laboulbeniaceae Part V. Mem Am Acad Arts Sci. 1931;16:1-435

23. Thaxter R. New Laboulbeniales, chiefly dipterophilous American species. Proc Am Acad Arts Sci. 1917;52:649-721.

24. Dittmar K, Porter ML, Murray S, Whiting MF. Molecular phylogenetic analysis of nycteribiid and streblid bat flies (Diptera: Brachycera, Calyptratae): implications for host associations and phylogeographic origins. Mol Phylogen Evol. 2006:38:155-70.

25. Haelewaters D, Boer P, Gort G, Noordijk J. Studies of Laboulbeniales (Fungi, Ascomycota) on Myrmica ants (II): variation of infection by Rickia wasmannii over habitats and time. Anim Biol. 2015;65:219-31.

26. Haelewaters D, Boer P, Noordijk J. Studies of Laboulbeniales (Fungi: Ascomycota) on Myrmica ants: Rickia wasmannii has different main hosts across geographic regions. J Hymenoptera Res. 2015;44:39-47.

27. Riddick EW. Influence of host gender on infection rate, density and distribution of the parasitic fungus, Hesperomyces virescens, on the multicolored Asian lady beetle, Harmonia axyridis. J Insect Sci. 2006;6:1-15.

28. Haelewaters D, Gorczak M, Pfliegler WP, Tartally A, Tischer M, Wrzosek M, Pfister DH. Bringing Laboulbeniales into the 21st century: enhanced techniques for extraction and PCR amplification of DNA from minute ectoparasitic fungi. IMA fungus. 2015;6:363-72.

29. Jére C, Szodoray-Parádi F. Identification guide for bat species (Chiroptera) of Romania. Satu Mare: APLR; 2010.

30. Williamson K. The Fair Isle apparatus for collecting bird ectoparasites. Brit Birds. 1954:47:235-6.

31. Theodor O. An illustrated catalogue of the Rothschild collection of Nycteribiidae in the British Museum (Natural History), with keys and short descriptions for the identification of subfamilies, genera, species and subspecies. London: British Museum (Natural History) Publication; 1967.

32. Theodor O, Moscona A. On bat parasites in Palestine. I. Nycteribiidae, Streblidae, Hemiptera, Siphonaptera. Parasitology. 1954:44:157-245.

33. Thaxter R. Contribution toward a monograph of the Laboulbeniaceae. Part II. Mem Am Acad Arts Sci. 1908;13:217-469

34. Landvik S, Egger KN, Schumacher T. Towards a subordinal classification of the Pezizales. Nord J Bot. 1997;17:403-18.

35. White TJ, Bruns TD, Lee SB, Taylor JW. Analysis of phylogenetic relationships by amplification and direct sequencing of ribosomal RNA genes. In: Innis MA, Gelfand DH, Sninsky JJ, White TJ, editors. PCR Protocols: a guide to methods and applications. San Diego: Academic; 1990. p. 315-22.

36. Miadlikowska J, Lutzoni F. Phylogenetic revision of the genus Peltigera (lichen-forming Ascomycota) based on morphological, chemical, and large subunit nuclear ribosomal DNA data. Int J Plant Sci. 2000;161:925-58.

37. Vilgalys $R$, Hester M. Rapid genetic identification and mapping of enzymatically amplified ribosomal DNA from several Cryptococcus species. J Bacteriol. 1990;172:4238-46

38. Tavares II. Laboulbeniales (Fungi, Ascomycetes). Mycol Mem. 1985;9:1-627.

39. Majewski T. The Laboulbeniales of Poland. Pol Bot Stud. 1994;7:1-466.

40. Bates $D$, Maechler M, Bolker B, Walker S. Fitting linear mixed-effects models using Ime4. J Stat Softw. 2015;67:1-48.

41. Dormann CF, Gruber B, Fründ J. Introducing the bipartite package: Analysing ecological networks. R News. 2008;8:8-11.

42. Szentiványi T, Estók P, Földvári M. Checklist of host associations of European bat flies (Diptera: Nycteribiidae, Streblidae). Zootaxa. 2016;4205:101-26.

43. Goldmann L, Weir A. Position specificity in Chitonomyces (Ascomycota, Laboulbeniomycetes) on Laccophilus (Coleoptera, Dytiscidae): a molecular approach resolves a century-old debate. Mycologia. 2012;104:1143-58.

44. Adamčík S, Caboň M, Eberhardt U, Saba M, Hampe F, Slovák M, et al. A molecular analysis reveals hidden species diversity within the current concept of Russula maculata (Russulaceae, Basidiomycota). Phytotaxa. 2016;270:71-88.

45. Cai L, Giraud T, Zhang N, Begerow D, Cai G, Shivas RG. The evolution of species concepts and species recognition criteria in plant pathogenic fungi. Fungal Divers. 2011;50:121-33.

46. Geml J, Tulloss RE, Laursen GA, Sazanova NA, Taylor DL. Evidence for strong inter- and intracontinental phylogeographic structure in Amanita muscaria, a wind-dispersed ectomycorrhizal basidiomycete. Mol Phylogenet Evol. 2008;48:694-701
47. De Kesel A, Haelewaters D. Laboulbenia slackensis and L. littoralis sp. nov. (Ascomycota, Laboulbeniales), two sibling species as a result of ecological speciation. Mycologia. 2014;106:407-14.

48. De Kesel A. Host specificity and habitat preference of Laboulbenia slackensis. Mycologia. 1996;88:565-73.

49. Pfliegler WP, Báthori F, Haelewaters D, Tartally A. Studies of Laboulbeniales on Myrmica ants (III): myrmecophilous arthropods as alternative hosts of Rickia wasmannii. Parasite. 2016;23:50.

50. Thaxter R. Contribution towards a monograph of the Laboulbeniaceae. Part III. Mem Am Acad Arts Sci. 1924;14:309-426

51. Benjamin RK. Introduction and supplement to Roland Thaxter's contribution toward a monograph of the Laboulbeniaceae. Biblioth Mycol. 1971;80:1-155.

52. Reboleira ASPS, Fresneda J, Salgado JM. A new species Of Speonemadus from Portugal with the revision of the escalerai-group (Coleoptera: Leiodidae). Eur J Taxon. 2017:261:1-23.

53. Dietz C, Kiefer A. Bats of Britain and Europe. London: Bloomsbury Publishing; 2016.

54. Lourenço SI, Palmeirim JM. How do ectoparasitic nycteribiids locate their bat hosts? Parasitology. 2008;135:1205-13.

55. Christe P, Glaizot O, Evanno G, Bruyndonckx N, Devevey G, Yannic G, et al. Host sex and ectoparasites choice: preference for, and higher survival on female hosts. J Anim Ecol. 2007:76:703-10.

56. Dick CW, Gannon MR, Little WE, Patrick MJ. Ectoparasite associations of bats from central Pennsylvania. J Med Entomol. 2003;40:813-9.

57. Kanuch P, Kristin A, Kristofik J. Phenology, diet, and ectoparasites of Leisler's bat (Nyctalus leisleri) in the western Carpathians (Slovakia). Acta Chiropterol. 2005;7:249-57.

58. Lourenço S, Palmeirim JM. Which factors regulate the reproduction of ectoparasites of temperate-zone cave-dwelling bats? Parasitol Res. 2008;104:127-34.

59. Lučan RK. Relationships between the parasitic mite Spinturnix andegavinus (Acari: Spinturnicidae) and its bat host, Myotis daubentonii (Chiroptera: Vespertilionidae): seasonal, sex- and age-related variation in infestation and possible impact of the parasite on the host condition and roosting behaviour. Folia Parasitol. 2006:53:147-52.

60. Presley SJ, Willig MR. Intraspecific patterns of ectoparasite abundances on Paraguayan bats: effects of host sex and body size. J Trop Ecol. 2008;24:75-83.

61. Dick CW, Patterson BD. An excess of males: skewed sex ratios in bat flies (Diptera: Streblidae). Evol Ecol. 2008;22:757-69.

62. Garcés S, Williams R. First record of Hesperomyces virescens Thaxter (Laboulbeniales: Ascomycetes) on Harmonia axyridis (Pallas) (Coleoptera: Coccinellidae). J Kansas Entomol Soc. 2004;77:156-8.

63. Nalepa CA, Weir A. Infection of Harmonia axyridis (Coleoptera: Coccinellidae) by Hesperomyces virescens (Ascomycetes: Laboulbeniales): Role of mating status and aggregation behavior. J Invert Pathol. 2007;94:196-203.

64. Welch VL, Sloggett JJ, Webberley KM, Hurst GDD. Short-range clinal variation in the prevalence of a sexually transmitted fungus associated with urbanisation. Ecol Entomol. 2001;26:547-50.

65. De Kesel A, Haelewaters D. Belgian records of Laboulbeniales from aquatic insects (3) - species from Dryops luridus. Sterbeeckia. 2014;33:9-15.

66. De Kesel A. Laboulbeniales (Ascomycetes) from coprohilic coleoptera on Galloway cow dung in Belgium. Pol Bot J. 2011;55:353-8.

67. Marshall AG. The life cycle of Basilia hispida Theodor 1967 (Diptera: Nycteribiidae) in Malaysia. Parasitology. 1970;61:1-18.

68. Rogers DJ, Randolph SE. Metabolic strategies of male and female tsetse (Diptera: Glossinidae) in the field. Bull Entomol Res. 2009;68:639-54.

69. Dean RL, Locke MI, Collins JV. Structure of the fat body. Comprehensive insect physiology, biochemistry and pharmacology. 1985;3:155-210

70. Arrese EL, Soulages JL. Insect fat body: Energy, metabolism, and regulation. Ann Rev Entomol. 2010;55:207-25. 